\title{
Calprotectin and TNF trough serum levels identify power Doppler ultrasound synovitis in rheumatoid arthritis and psoriatic arthritis patients in remission or with low disease activity
}

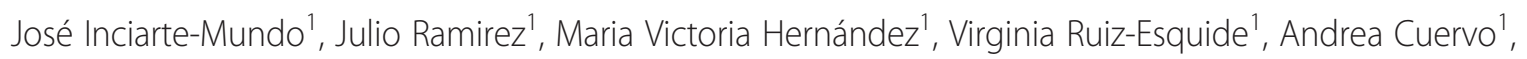
Sonia Raquel Cabrera-Villalba ${ }^{1}$, Mariona Pascal ${ }^{2}$, Jordi Yagüe ${ }^{2}$, Juan D. Cañete ${ }^{1}$ and Raimon Sanmarti ${ }^{*}$

\begin{abstract}
Background: Serum levels of calprotectin, a major S100 leucocyte protein, are associated with disease activity in rheumatoid arthritis (RA) and psoriatic arthritis (PsA) patients. Higher drug trough serum levels are associated with good response in patients treated with tumour necrosis factor inhibitors (TNFi). Power Doppler ultrasound (PDUS) synovitis is predictive of flare and progression of structural damage in patients in clinical remission. The purpose of this study was to analyse the accuracy of calprotectin and TNFi trough serum levels in detecting PDUS synovitis in RA and PSA patients in clinical remission or with low disease activity who were receiving TNFi.

Methods: We conducted a cross-sectional study of 92 patients (42 with RA, 50 with PsA) receiving adalimumab (ADA), etanercept (ETN) or infliximab who were in remission or had low disease activity (28-joint Disease Activity Score based on erythrocyte sedimentation rate <3.2). Associations of calprotectin, TNFi trough serum levels and acute phase reactants with PDUS synovitis were assessed using correlation and linear regression analyses. The accuracy and discriminatory capacity in detecting PDUS synovitis was assessed using ROC curves.

Results: PDUS synovitis was found in $62.4 \%$ of RA patients and $32 \%$ of PsA patients. Both RA and PsA patients with PDUS synovitis had higher calprotectin levels and lower TNFi trough serum levels. Calprotectin positively correlated with ultrasound scores (all $r$ coefficients $>0.50$ in RA). Calprotectin correlated with the PDUS synovitis score in patients treated with ADA and ETN. Using PDUS synovitis (yes or no) as the reference variable, calprotectin had an AUC of 0.826 . The best cut-off was $\geq 1.66 \mu \mathrm{g} / \mathrm{ml}$, with a likelihood ratio of 2.77. C-reactive protein (AUC 0.673 ) and erythrocyte sedimentation rate (AUC 0.731) had a lower discriminatory capacity. TNFi trough serum levels were significantly associated with PDUS synovitis (OR 0.67, $95 \% \mathrm{Cl} 0.52-0.85, p<0.001)$ but their accuracy $(A \cup C<0.5)$ was less than that of calprotectin. TNFi trough serum levels were inversely correlated with calprotectin and PDUS synovitis in RA and PSA patients receiving ADA and ETN.
\end{abstract}

Conclusions: Calprotectin and TNFi trough serum levels may help identify PDUS synovitis in RA and PSA patients in clinical remission or with low disease activity.

Keywords: Calprotectin, TNFi trough serum levels, Ultrasound, Disease activity, Rheumatoid arthritis, Psoriatic arthritis

\footnotetext{
*Correspondence: sanmarti@clinic.cat

'Department of Rheumatology, Hospital Clinic, University of Barcelona, Carrer

Villarroel 170, 08036 Barcelona, Spain

Full list of author information is available at the end of the article
} 


\section{Background}

New therapeutic strategies, including early therapy, treatto-target approaches and biological therapies, have led to substantial improvements in the prognosis of patients with rheumatoid arthritis (RA) and other types of inflammatory arthritis, such as ankylosing spondylitis and psoriatic arthritis (PsA) [1]. These strategies have enabled patients to reach clinical remission (i.e., the absence of clinically detectable joint inflammation), which is now a realistic therapeutic goal in clinical practice [2]. However, there is no consensus on what constitutes clinical remission and which indices should be used to measure it, and therefore rates of clinical remission depend on the articular index used. Furthermore, most patients in clinical remission have evidence of inflammatory activity, especially when less stringent criteria are used [3-6].

Musculoskeletal ultrasound (MSUS), a non-invasive diagnostic technique, is widely used in rheumatology to measure joint inflammation with greater sensitivity [7]. Power Doppler (PD) detects synovial flow, a sign of increased synovial vascularization, and better reflects active synovial inflammation compared with synovial hypertrophy $(\mathrm{SH})$ [8]. PD correlates with disease activity and decreases after treatment, and it is therefore sensitive to change [9-11]. MSUS has revealed that a significant proportion of patients classified as being in clinical remission exhibit power Doppler ultrasound (PDUS) synovitis, which may explain the joint damage progression observed in some patients despite no clinical findings of disease activity. In addition, PDUS synovitis is predictive of clinical flares [12-15].

In rheumatology, promising biomarkers that more accurately reflect the clinical status, including remission, of patients with inflammatory arthritis have been recognized. Use of these biomarkers might enhance clinical practice and guide therapeutic decisions. Recently, serum calprotectin, a heterodimeric complex of two S100 calcium-binding myeloid-related proteins (MRP8 [or S100A8] and MRP14 [or S100A9]), has been reported to be a sensitive biomarker of disease activity in patients with RA and patients with spondyloarthritis [16]. Calprotectin is an important proinflammatory factor of innate immunity, acting as endogenous damageassociated molecular pattern molecules via Toll-like receptor 4 activation [17]. Higher calprotectin levels have been found in the synovial fluid and serum of RA and PsA patients [18]. Serum calprotectin levels correlate with disease activity and are independently associated with radiographic progression in RA [19-21]. Levels decrease significantly after treatment with tumour necrosis factor inhibitors (TNFi) and might be useful in monitoring biological therapy [22, 23].

Recent studies have found a significant dose-response relationship between the extent of clinical improvement and TNFi trough serum levels [24, 25], with higher drug trough serum levels being associated with good responses due to significant decreases in disease activity [26], less progression of joint damage [27] and reductions in acute phase response proteins such as Creactive protein (CRP) [28].

The aim of this study was to analyse the accuracy of calprotectin serum levels and TNFi trough serum levels in detecting PDUS synovitis in RA and PsA patients in clinical remission or with low disease activity who were receiving TNFi.

\section{Methods}

This cross-sectional study included consecutive RA (American College of Rheumatology 1987 criteria) and polyarticular PsA (CASPAR, ClASsification criteria for Psoriatic Arthritis) patients from our arthritis unit. All patients were in remission (28-joint Disease Activity Score based on erythrocyte sedimentation rate [DAS28ESR] $\leq 2.6)$ or had low disease activity (DAS28-ESR $\leq 3.2$ ) in two consecutive visits $\geq 3$ months apart and had been taking adalimumab (ADA), etanercept (ETN) or infliximab (IFX) for $\geq 3$ months. Patients with DAS28-ESR $>3.2$ or PsA patients with axial or entheseal involvement or an oligoarticular peripheral pattern were excluded. Information collected comprised demographic data, disease duration, autoantibody status, radiological data, concomitant conventional synthetic disease-modifying anti-rheumatic drug (csDMARD) therapy, and dose and duration of biological therapy. Some patients were receiving reduced-dose biological therapy due to persistent remission and/or low disease activity. A reduced dose was defined as treatment with a Lower amount of the drug or longer interval of administration than recommended in each product package insert.

\section{Measurement of disease activity}

Before MSUS assessment, all patients underwent a clinical assessment including 28-joint swollen and tender joint counts as well as physician and patient global assessments with visual analogue scales $(0-100 \mathrm{~mm})$. Three composite disease activity indices were subsequently calculated: DAS28-ESR [29, 30], Simple Disease Activity Index [31] and Clinical Disease Activity Index [32].

\section{Ultrasound assessment}

Sonographic assessments were carried out using highsensitivity ultrasound equipment (MyLab Twice ${ }^{\oplus}$; Esaote, Genoa, Italy), with a frequency range from 10 to $14 \mathrm{MHz}$ and a pulse repetition frequency between 500 and $800 \mathrm{~Hz}$. Receiver gain settings were controlled to eliminate artefacts. Joint MSUS findings were defined according to published Outcome Measures in Rheumatoid Arthritis Clinical Trials (OMERACT) definitions [33]. A 
single experienced sonographer (JR) who was blinded to the results of the clinical joint examination evaluated 11 joints and tendons of each hand (including proximal interphalangeal joints, metacarpophalangeal joints, and wrists) for both $\mathrm{SH}$ and intra-articular PD signalling according to European League Against Rheumatism guidelines [34]. SH and PD signals were graded using a four-grade semi-quantitative scoring system $(0=$ no, $1=$ mild, $2=$ moderate and $3=$ severe) according the methodology of Szkudlarek et al [35]. Intra-rater agreement on MSUS assessment, calculated as previously described [36], were 0.83 for $\mathrm{SH}$ and 0.90 for PD.

By summing the scores for elementary lesions in each joint, we calculated the PD score (sum of PD scores in all joints, range 0-66), the $\mathrm{SH}$ score (sum of $\mathrm{SH}$ scores in all joints, range 0-66) and the global score (sum of the PD and SH scores, range 0-132). PDUS synovitis was defined as a PD signal in synovial tissue [37]. A more stringent definition of active synovitis (ultrasounddefined active synovitis [UdAS]) developed by our group ( $\mathrm{SH}$ grade $\geq 2$ plus PDUS synovitis signal) was also recorded. UdAS patients showed significantly higher serum levels of several angiogenic factors thought to be relevant to RA pathogenesis. Clinically, UdAS-positive patients showed greater disease activity on the basis of composite indices different from those used for UdASnegative patients [36].

\section{Measurement of serum calprotectin levels, acute phase response and TNFi trough serum levels}

Blood samples were collected immediately before the next administration of TNFi, centrifuged 20 minutes after sample collection to separate serum and plasma, and stored at $-80{ }^{\circ} \mathrm{C}$ until analysis. Calprotectin serum levels were determined using an enzyme-linked immunosorbent assay (ELISA) test kit (CALPROLAB Calprotectin ELISA (ALP); Calpro AS, Lysaker, Norway) in accordance with the manufacturer's protocol. Briefly, $100 \mathrm{ml}$ of each standard, control and diluted 1:20 sample in duplicate wells were incubated at room temperature for 40 minutes. Three washings were done, $100 \mathrm{ml}$ of the conjugated enzyme were added, and the plates were incubated at room temperature for 40 minutes. After three washes and the addition of the enzyme substrate, the optical density values at $405 \mathrm{~nm}$ were determined using an ELISA reader. To reduce variation in calprotectin determination, the whole procedure was performed in a Triturus ${ }^{\oplus}$ autoanalyzer (Diagnostic Grifols, Barcelona, Spain) [38]. ESR was measured using the Westergren method (Normal Value (NV) $<20 \mathrm{~mm} / \mathrm{h}$ ), and CRP was measured by nephelometry (lowest detection limit $0.01 \mathrm{mg} / \mathrm{dl}, \mathrm{NV}<0.8 \mathrm{mg} / \mathrm{dl})$. Trough serum levels of ETN, ADA and IFX were measured by using a bridging ELISA (Promonitor; Progenika Biopharma, Derio, Spain) that has been validated and shows adequate correlation in measuring drug levels and anti-drug antibodies [39].

The study was conducted in accordance with the Declaration of Helsinki and was approved by the Hospital Clinic of Barcelona Clinical Research Ethics Committee (Reg. 2013/8382). Signed informed consent was obtained from all patients before study enrolment.

\section{Statistical analysis}

Continuous data were presented as medians and ranges, and categorical variables were presented as absolute frequencies and percentages. Groups were compared using Student's $t$ test or the Mann-Whitney $U$ test when appropriate. Correlations were assessed using Spearman's correlation coefficient. Logistic regression models were used to assess associations between calprotectin, TNFi trough serum levels and PDUS synovitis, using ultrasound (US) as the dependent variable and calprotectin and TNFi trough serum levels as independent factors. Crude ORs with 95 \% CIs were calculated. Multivariate models were constructed to analyse the effect of covariates and to fully adjust the association between calprotectin, TNFi trough serum levels and PDUS synovitis. Models were fitted separately and compared using the Akaike information criterion and the Bayesian information criterion. The discriminatory capacity of calprotectin, TNFi trough serum levels, CRP and ESR, with PDUS synovitis (yes or no) as the gold standard, was analysed using ROC curves, and the best cut-off in terms of sensitivity and specificity was identified. The predictive values, accuracy and positive likelihood ratio were calculated. The AUC was estimated using Hanley's corrected confidence intervals. The analyses were carried out using STATA version 11 software (StataCorp, College Station, TX, USA).

\section{Results}

Ninety-two patients were included (42 RA, 50 PsA), and their median disease duration was 15 (1-44) years. Forty-four patients were receiving ETN (22 RA and 22 PsA), 32 were taking ADA (14 RA and 18 PsA) and 16 were receiving IFX (6 RA and 10 PsA). The median biological treatment duration was $63.4(12-166)$ months, and 42 patients had received a reduced dose of biological therapy. Seventy-one patients $(77.2 \%)$ were in remission, and $21(22.8 \%)$ had low disease activity. PsA patients included were younger, had a shorter duration of biological therapy, and had lower percentages of csDMARD and steroid use than RA patients (Table 1).

Power Doppler ultrasound synovitis and disease status Forty-three patients (46.7 \%) had PDUS synovitis (27 RA [64.2\%] and 16 PsA [32 \%]), of whom 15 (10 RA [23.8\%] and 5 PsA [10 \%]) met the criteria for UdAS 
Table 1 Patients and disease characteristics

\begin{tabular}{|c|c|c|c|c|}
\hline Patient characteristics & Total $(n=92)$ & $\mathrm{RA}(n=42)$ & $\operatorname{PsA}(n=50)$ & $p$ Value \\
\hline Female sex, $n(\%)$ & $59(64.1)$ & $34(81)$ & $25(50)$ & 0.158 \\
\hline Age, years, median (range) & $58(30-81)$ & $63.5(30-81)$ & $54.5(33-77)$ & $<0.001$ \\
\hline Body index mass, $\mathrm{kg} / \mathrm{m}^{2}$, median (range) & $26.4(18-42)$ & $26.2(19.2-42)$ & $26.6(18.3-35)$ & 0.189 \\
\hline Disease duration, years, median (range) & $15(1-44)$ & $15.5(2-44)$ & $14.5(1-36)$ & 0.785 \\
\hline Presence of erosions, $n(\%)$ & $53(57.6)$ & $33(78.6)$ & $20(40)$ & 0.012 \\
\hline At least one previous biological treatment, $n(\%)$ & $28(27)$ & $11(26)$ & $14(28)$ & 0.552 \\
\hline Concomitant csDMARD, $n$ (\%) & $47(51.1)$ & $32(76.2)$ & $15(30)$ & 0.005 \\
\hline Concomitant steroids, $n$ (\%) & $15(16.3)$ & $13(31)$ & $2(4)$ & $<0.001$ \\
\hline Prednisone dose, mg/day, median (range) & $2.5(3-5)$ & $2.5(3-5)$ & $3.7(3-5)$ & 0.152 \\
\hline Biological treatment duration, months, median (range) & $64.8(12-166)$ & $83.2(9-165)$ & $58.3(7.6-166)$ & 0.017 \\
\hline Reduced dosage, ${ }^{a} n(\%)$ & $42(45.7)$ & $12(28.6)$ & $30(60)$ & $<0.001$ \\
\hline Albumin, g/dl, median (range) & $42.5(30-49)$ & $32(30-49)$ & $47(30-49)$ & 0.005 \\
\hline CRP, mg/dl, median (range) & $0.095(0.01-1.45)$ & $0.10(0.01-1.4)$ & $0.09(0.01-0.6)$ & 0.288 \\
\hline $\mathrm{ESR}, \mathrm{mm} / \mathrm{h}$, median (range) & $10(2-43)$ & $12.5(2-43)$ & $8.5(2-32)$ & 0.004 \\
\hline Calprotectin, $\mu \mathrm{g} / \mathrm{ml}$, median (range) & $1.67(0.06-5.54)$ & $2.16(0.2-5.5)$ & $1.36(0.06-4.6)$ & 0.002 \\
\hline SJC, median (range) & $0(0-3)$ & $0(0-3)$ & $0(0-2)$ & 0.625 \\
\hline TJC, median (range) & $0(0-2)$ & $0(0-2)$ & $0(0-1)$ & 0.788 \\
\hline DAS28-ESR, median (range) & $1.96(1.0-3.2)$ & $2.31(1.3-3.2)$ & $1.82(1-3.1)$ & $<0.001$ \\
\hline Remission based on DAS28-ESR, $n$ (\%) & $71(77.2)$ & $27(64.3)$ & $44(88)$ & 0.005 \\
\hline Low disease activity based on DAS28-ESR, $n(\%)$ & $21(22.8)$ & $15(35.7)$ & $6(12)$ & 0.005 \\
\hline CDAl, median (range) & $6(2-11.0)$ & $6(2-11)$ & $6(2-8)$ & 0.782 \\
\hline SDAl, median (range) & $6(2-11.1)$ & $6(2-11)$ & $6(2-8)$ & 0.005 \\
\hline
\end{tabular}

Abbreviations: CDAI Clinical Disease Activity Index, CRP C-reactive protein, CSDMARD conventional synthetic disease-modifying anti-rheumatic drug, DAS28-ESR 28-joint Disease Activity Score based on erythrocyte sedimentation rate, ESR erythrocyte sedimentation rate, PSA psoriatic arthritis, $R A$ rheumatoid arthritis, SDAI Simple Disease Activity Index, SJC swollen joint count, TJC tender joint count

${ }^{a}$ Treatment regimen with a lesser amount of the drug or longer interval of administration than those recommended in the package insert for each product

(SH grade $\geq 2$ plus PDUS synovitis signal). Patients with PDUS synovitis were mostly female, had a diagnosis of RA, were more frequently treated with steroids, and had a higher percentages of low disease activity according to all indices assessed (Table 2). Similar results were obtained when UdAS criteria were applied (data not shown).

\section{Calprotectin, acute phase reactants and power Doppler ultrasound synovitis}

Patients with PDUS synovitis had higher levels of calprotectin (PDUS-negative $[n=49] 1 \mu \mathrm{g} / \mathrm{ml}$ [0.6-3.7] vs. PDUS-positive $[n=43] 2.68 \mu \mathrm{g} / \mathrm{ml}[0.22-5.5], p<0.001)$, CRP (PDUS-negative $[n=49] 0.07 \mathrm{mg} / \mathrm{dl}[0.1-0.6]$ vs. PDUS-positive $[n=43] 0.20 \mathrm{mg} / \mathrm{dl}[0.01-1.4], p=0.005)$ and ESR (PDUS-negative $[n=49] 8 \mathrm{~mm} / \mathrm{h}$ [2-29] vs. PDUS-positive $[n=43] 13 \mathrm{~mm} / \mathrm{h} \quad[2-43], p<0.001)$. Similar results were obtained when patients were analysed according to diagnosis (RA vs. PsA), although no significant differences in CRP levels were observed between PsA patients with versus without PDUS synovitis (Table 2).
When a more stringent active synovitis criterion (UdAS) was applied, calprotectin (UdAS $[n=15] 3.48 \mu \mathrm{g} / \mathrm{ml}[0.2-$ 5.5] vs. non-UdAS [ $n=77] 1.47 \mu \mathrm{g} / \mathrm{ml}$ [0.06-4.8], $p<$ 0.001 ), but not CRP (UdAS [ $n=15] 0.11 \mathrm{mg} / \mathrm{dl}[0.05-0.24]$ vs. non-UdAS [ $n=77] 0.09 \mathrm{mg} / \mathrm{dl}$ [0.07-0.13], $p=0.699)$ or ESR (UdAS [ $n=15] 12.8 \mathrm{~mm} / \mathrm{h}$ [8.1-20.1] vs. non-UdAS [n=77] $9.6 \mathrm{~mm} / \mathrm{h}$ [8.3-10.9], $p=0.108)$ distinguished patients with UdAS from those without UdAS.

Calprotectin strongly correlated with MSUS scores (all $r$ coefficients $>0.50$ in RA patients). A weak correlation was found between ESR and joint indices and MSUS scores, while CRP correlated only with the PD score in RA (Table 3). Calprotectin correlated with the PD score in patients treated with ADA $(\rho=-0.591, p<0.001)$ and ETN $(\rho=-0.313, p=0.039)$, but not in those treated with IFX.

The accuracy analysis with PDUS synovitis (yes or no) as the reference variable showed an AUC of 0.826 (95\% CI 0.742-0.910) and a cut-off calprotectin level of $1.66 \mu \mathrm{g} / \mathrm{ml}$ (sensitivity $79.1 \%$, specificity $83.4 \%$ ). The positive likelihood ratio of this calprotectin level for PDUS synovitis was 2.77; the negative likelihood ratio 
Table 2 Calprotectin, disease activity, ultrasound assessment and tumour necrosis factor inhibitor trough serum levels according to diagnosis

\begin{tabular}{|c|c|c|c|c|}
\hline \multirow[t]{2}{*}{ Patient characteristics } & \multicolumn{2}{|l|}{ RA $(n=42)$} & \multicolumn{2}{|l|}{$\operatorname{PsA}(n=50)$} \\
\hline & PDUS-negative $(n=15)$ & PDUS-positive $(n=27)$ & PDUS-negative $(n=34)$ & PDUS-positive $(n=16)$ \\
\hline Female sex, $n(\%)$ & $11(73.3)$ & $23(85.2)$ & $15(44.1)$ & $10(62.5)^{\mathrm{a}}$ \\
\hline Age, years, median (range) & $62(49-78)$ & $64(30-81)$ & $53(33-77)$ & $55(40-72)$ \\
\hline Disease duration, years, median (range) & $13(8-28)$ & $17(2-44)$ & $13.5(1-28)$ & $16(3-36)$ \\
\hline Concomitant csDMARD, $n$ (\%) & $11(73.3)$ & $21(77.8)$ & $11(32.4)$ & $4(25)$ \\
\hline Reduced dose, $n$ (\%) & $4(26.7)$ & $8(29.6)$ & $21(61.8)$ & $9(56.3)$ \\
\hline Calprotectin, $\mu \mathrm{g} / \mathrm{ml}$, median (range) & $1.44(0.2-2.4)$ & $2.95(0.2-5.5)^{\mathrm{a}}$ & $0.70(0.06-3.7)$ & $2.36(0.9-4.6)^{b}$ \\
\hline CRP, mg/dl, median (range) & $0.07(0.02-0.1)$ & $0.30(0.01-1.4)^{\mathrm{a}}$ & $0.08(0.01-0.6)$ & $0.09(0.01-0.3)$ \\
\hline ESR, mm/h, median (range) & $10(2-24)$ & $13(2-43)$ & $8(2-29)$ & $13(4-32)^{a}$ \\
\hline SJC, median (range) & $0(0-1)$ & $0(0-3)$ & $0(0-1)$ & $0(0)$ \\
\hline TJC, median (range) & $0(0-1)$ & $0(0-2)$ & $0(0-1)$ & $0(0-1)$ \\
\hline DAS28-ESR, median (range) & $2.08(1.5-2.6)$ & $2.62(1.3-3.2)^{\mathrm{a}}$ & $1.67(1-2.7)$ & $2.15(1.1-3.1)^{\mathrm{a}}$ \\
\hline Remission based on DAS28-ESR, $n$ (\%) & $13(86.7)$ & $14(51.9)^{b}$ & $9(90)$ & $6(75)^{a}$ \\
\hline Low disease activity based on DAS28-ESR, $n(\%)$ & $2(13.3)$ & $13(48.1)^{b}$ & $1(10)$ & $2(25)$ \\
\hline SDAl, median (range) & $6.02(2-8)$ & $6.26(2-11)^{\mathrm{a}}$ & $5.10(2-8)$ & $6.04(2-8.3)$ \\
\hline CDAl, median (range) & $6(2-8)$ & $6(2-11)$ & $5(2-8)$ & $6(2-8)$ \\
\hline ADA trough serum levels, $\mu \mathrm{g} / \mathrm{ml}$, median (range) & $8.39(4.2-12)$ & $1.68(0.6-12)^{a}$ & $6.95(4.1-12)$ & $0.88(0.2-9.8)^{a}$ \\
\hline ETN trough serum levels, $\mu \mathrm{g} / \mathrm{ml}$, median (range) & $2.54(0.2-4.7)$ & $0.98(0.7-2.3)^{a}$ & $1.38(01-3.5)$ & $0.91(0.6-1.6)^{a}$ \\
\hline IFX trough serum levels, $\mu \mathrm{g} / \mathrm{ml}$, median (range) & $8.39(4.2-12)$ & $1.68(0.6-12)^{a}$ & $3.21(0.7-7.7)$ & $2.86(0.1-6.5)$ \\
\hline
\end{tabular}

Abbreviations: $A D A$ adalimumab, CDAl Clinical Disease Activity Index, CRP C-reactive protein, CSDMARD conventional synthetic disease-modifying anti-rheumatic drug, DAS28-ESR 28-joint Disease Activity Score based on erythrocyte sedimentation rate, ESR erythrocyte sedimentation rate, ETN etanercept, IFX infliximab, PDUS power Doppler ultrasound, PSA psoriatic arthritis, RA rheumatoid arthritis, SDAI Simple Disease Activity Index, SJC swollen joint count, TJC tender joint count ${ }^{\mathrm{a}} p<0.05$

$\mathrm{b}_{p}<0.001$

was 2.29; and these values correctly classified PDUS synovitis in $85 \%$ of patients (Fig. 1). CRP (AUC 0.673) and ESR (AUC 0.731) had a lower discriminatory capacity than calprotectin. An accuracy analysis for DAS28CRP using PDUS synovitis as the reference variable was also performed. ROC analysis showed a lower accuracy than calprotectin, with an AUC of 0.721 (95 \% CI 0.612$0.829, p=0.005)$ and a cut-off DAS28-CRP value of 1.61 (sensitivity $72 \%$, specificity $61 \%$, positive likelihood ratio 1.85 , negative likelihood ratio 0.45 ), and it correctly classified PDUS synovitis in $66.3 \%$ of patients.

Adjusted multivariate regression analysis showed a strong association between calprotectin and PDUS synovitis (OR 4.6, 95 \% CI 2.31-9.26, $p<0.001$ ) according to the different covariates (combined therapy, reduced dose, use of glucocorticoids, disease duration, and presence of autoantibodies or erosive disease). Backward selection of variables did not substantially modify the association between calprotectin and PDUS synovitis (Table 4). Other variables associated with PDUS synovitis were long-standing disease (OR 1.10, 95 \% CI 1.02$1.18, p<0.001)$ and steroid use (OR 18.1, 95 \% CI 2.73$120.2, p<0.005)$.

\section{TNFi trough serum levels and power Doppler ultrasound synovitis}

RA patients with PDUS synovitis had significantly lower ETN, ADA and IFX trough serum levels. PsA patients with PDUS synovitis had lower trough serum levels of ETN and ADA but not IFX (Table 2). ADA and ETN, but not IFX, trough serum levels inversely correlated with PDUS and MSUS global scores. Similar results were obtained for UdAS (Table 5).

Although adjusted multivariate regression analysis showed that lower TNFi trough serum levels were significantly associated with PDUS synovitis (OR 0.67, $95 \%$ CI $0.52-0.85, p<0.001)$, TNFi trough serum levels had low accuracy (AUC $<0.5)$.

\section{Calprotectin and TNFi trough serum levels}

Calprotectin inversely correlated with ADA $(\rho=-0.461, p=$ $0.008)$ and $\operatorname{ETN}(\rho=-0.436, p=0.005)$ trough serum levels, although non-significant correlations were found for IFX.

\section{Discussion}

The results of this study show a significant proportion of patients with RA and PsA in remission or with low 
Table 3 Correlation between musculoskeletal ultrasound scores and calprotectin, acute phase reactants and disease activity indices

\begin{tabular}{|c|c|c|}
\hline & $\mathrm{RA}(n=42)$ & $\operatorname{PsA}(n=50)$ \\
\hline \multicolumn{3}{|l|}{ Doppler score } \\
\hline Calprotectin & $0.570^{\mathrm{a}}$ & $0.420^{b}$ \\
\hline CRP & $0.338^{b}$ & 0.058 \\
\hline ESR & 0.285 & $0.337^{\mathrm{b}}$ \\
\hline Albumin & -0.259 & $-0.322^{b}$ \\
\hline DAS28-ESR & $0.380^{\mathrm{b}}$ & $0.384^{b}$ \\
\hline SDAl & 0.126 & 0.071 \\
\hline CDAl & 0.080 & 0.115 \\
\hline \multicolumn{3}{|l|}{ SH score } \\
\hline Calprotectin & $0.589^{a}$ & $0.423^{b}$ \\
\hline CRP & 0.044 & 0.092 \\
\hline ESR & 0.217 & 0.020 \\
\hline Albumin & $-0.336^{b}$ & $-0.210^{b}$ \\
\hline DAS28-ESR & $0.423^{b}$ & $0.284^{b}$ \\
\hline SDAl & 0.275 & 0.217 \\
\hline CDAI & 0.163 & 0.277 \\
\hline \multicolumn{3}{|l|}{ Global score } \\
\hline Calprotectin & $0.641^{\mathrm{a}}$ & $0.446^{\mathrm{a}}$ \\
\hline CRP & 0.105 & 0.122 \\
\hline ESR & 0.226 & 0.111 \\
\hline Albumin & $-0.332^{b}$ & -0.237 \\
\hline DAS28-ESR & $0.446^{b}$ & $0.348^{b}$ \\
\hline SDAI & 0.280 & 0.195 \\
\hline CDAI & 0.172 & 0.266 \\
\hline
\end{tabular}

Abbreviations: CDAl Clinical Disease Activity Index, CRP C-reactive protein, DAS28-ESR 28-joint Disease Activity Score based on erythrocyte sedimentation rate, ESR erythrocyte sedimentation rate, PSA psoriatic arthritis, $R A$ rheumatoid arthritis, SDAI Simple Disease Activity Index, $S H$ synovial hypertrophy Data presented are Spearman's $\rho$ correlations ${ }^{\mathrm{a}} p<0.001$

${ }^{\mathrm{b}} p<0.05$

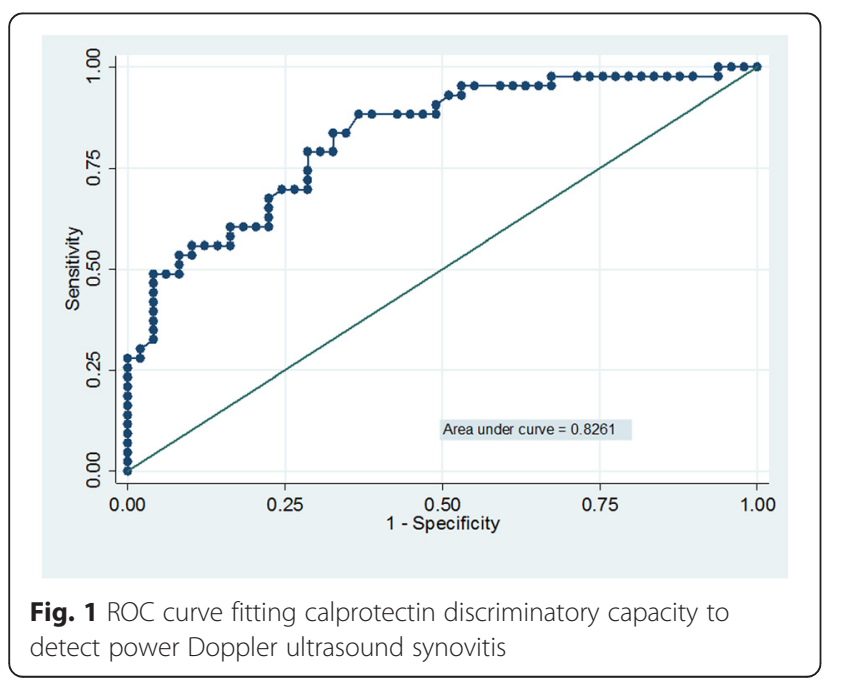

disease activity who were treated with TNFi had PDUS synovitis, together with significantly higher levels of serum calprotectin, which was more accurate than acute phase reactants (APRs) in identifying PDUS synovitis. Patients with PDUS synovitis had significantly lower TNFi serum levels, and there was an inverse correlation between TNFi serum levels and calprotectin in the two diseases. Therefore, calprotectin and TNFi serum levels may be considered as sensitive biomarkers of synovial inflammation in RA and PsA patients in remission or with low disease activity being treated with TNFi.

Developing standardized instruments to detect synovial inflammation in RA and PsA patients in remission or with low disease activity is a clinical challenge. MSUS, a noninvasive, relatively inexpensive, dynamic technique that allows real-time examination and more sensitive detection of joint inflammation than clinical examination [7], is sufficiently sensitive to measure changes in disease activity, thereby permitting the monitoring of therapeutic responses in patients receiving biological therapy [40].

An increasing amount of data supports the emerging role and clinical utility of imaging techniques such as MSUS in evaluating patients with inflammatory arthritis in clinical remission or with low disease activity. Clinical remission is known not to be equivalent to the absence of imaging-detected synovitis in RA. Only one-third of patients classified as being in clinical remission had a total absence of painful, swollen or tender joints, regardless of the criteria used, and most patients had ongoing active synovitis on the basis of MSUS [41], which may explain the continuing structural progression in some patients despite apparent clinical remission [42].

US-based findings in RA patients in remission should be interpreted with caution. Patients with grade $1 \mathrm{SH}$, especially those without $\mathrm{PD}$, could be considered to have non-pathologic disease and may be present in the healthy population [43]. In RA patients, $\mathrm{SH}$ could suggest the chronic anatomical changes of earlier synovitis rather than current synovial inflammation [44]. In contrast, the presence of PD has repeatedly demonstrated greater sensitivity in detecting active synovitis $[11,12$, $15,45]$. In our cohort, $64 \%$ of RA patients and $32 \%$ of PsA patients had PDUS synovitis, although only $24 \%$ of RA patients and $10 \%$ of PsA patients met the more stringent criteria of UdAS. We previously demonstrated that UdAS captured only patients with potentially clinically relevant symptoms and correlated with increased serum levels of angiogenic biomarkers [37].

Subjective clinical symptoms, joint examination and laboratory measurements of APR are not sufficiently sensitive to exclude ongoing inflammation in patients with low disease activity levels. TNFi improves the clinical signs of RA while reducing serum levels of CRP and ESR [46]. The reduction in APRs may be due in part to 
Table 4 Associations between calprotectin, tumour necrosis factor inhibitor trough serum levels and power Doppler ultrasound synovitis

\begin{tabular}{|c|c|c|c|c|}
\hline & Unadjusted $\beta$ coe & & Fully adjusted $\beta$ coe & \\
\hline & OR $(95 \% \mathrm{Cl})$ & $p$ Value & OR $(95 \% \mathrm{Cl})$ & $p$ Value \\
\hline Calprotectin, $\mu \mathrm{g} / \mathrm{ml}$ & $3.22(1.95-5.33)$ & $<0.0001$ & $4.63(2.31-9.26)$ & $<0.0001$ \\
\hline TNFi trough serum levels, $\mu \mathrm{g} / \mathrm{ml}$ & $0.77(0.65-0.91)$ & 0.002 & $0.67(0.52-0.85)$ & 0.001 \\
\hline Age, years & $1.03(0.99-1.06)$ & 0.164 & & \\
\hline Disease duration, years & $1.05(1.00-1.10)$ & 0.067 & $1.10(1.02-1.18)$ & 0.016 \\
\hline $\mathrm{ESR}, \mathrm{mm} / \mathrm{h}$ & $1.13(1.05-1.22)$ & 0.001 & & \\
\hline Female sex & $2.92(1.18-7.20)$ & 0.020 & & \\
\hline Combined therapy, yes or no & $1.64(0.72-3.76)$ & 0.245 & & \\
\hline Disease activity according to DAS28-ESR & & 0.001 & & \\
\hline Remission $(<2.6)$ & 1 & & & \\
\hline Low disease activity (2.6-3.2) & $7.35(2.23-24.21)$ & & & \\
\hline Reduced dose, yes or no & $0.63(0.27-1.44)$ & 0.271 & & \\
\hline Diagnostic & & 0.002 & & \\
\hline RA & 1 & & & \\
\hline PsA & $0.26(0.11-0.62)$ & & & \\
\hline Steroids, yes or no & $2.67(0.83-8.55)$ & 0.099 & $18.12(2.73-120.16)$ & 0.003 \\
\hline Monotherapy, yes or no & $0.59(0.26-1.34)$ & 0.206 & & \\
\hline Constant & & & $0.02(0.003-0.16)$ & $<0.0001$ \\
\hline
\end{tabular}

Abbreviations: DAS28-ESR 28-joint Disease Activity Score based on erythrocyte sedimentation rate, ESR erythrocyte sedimentation rate, PSA psoriatic arthritis, RA rheumatoid arthritis, TNFi tumour necrosis factor inhibitors

the direct systemic effect of TNFi on hepatic synthesis of CRP and other APRs, such as fibrinogen, rather than to true improvements in local joint synovitis. In contrast, calprotectin is released by activated phagocytes such as synovial monocytes and granulocytes [18], and its levels reflect local ongoing inflammation rather than a

Table 5 Correlation between musculoskeletal ultrasound scores and tumour necrosis factor inhibitor trough serum levels

\begin{tabular}{llll}
\hline & Total $(n=92)$ & RA $(n=42)$ & PsA $(n=50)$ \\
\hline Adalimumab & & & \\
Doppler score & $-0.842^{\mathrm{a}}$ & $-0.898^{\mathrm{a}}$ & $-0.803^{\mathrm{a}}$ \\
SH score & -0.329 & -0.447 & -0.107 \\
Global score & $-0.547^{\mathrm{b}}$ & $-0.639^{\mathrm{b}}$ & $-0.423^{\mathrm{b}}$ \\
Etanercept & & & \\
Doppler score & $-0.649^{\mathrm{a}}$ & $-0.543^{\mathrm{b}}$ & $-0.791^{\mathrm{a}}$ \\
SH score & -0.024 & -0.169 & -0.052 \\
Global score & $-0.504^{\mathrm{b}}$ & -0.251 & -0.362 \\
Infliximab & & & \\
Doppler score & -0.178 & -0.530 & -0.076 \\
SH score & -0.052 & -0.667 & -0.122 \\
Global score & -0.132 & $-0.870^{\mathrm{b}}$ & -0.060
\end{tabular}

PsA psoriatic arthritis, $R A$ rheumatoid arthritis, $S H$ synovial hypertrophy Data presented are Spearman's $\rho$ correlations

${ }^{a} p<0.001$

${ }^{\mathrm{b}} p<0.05$ systemic inflammatory response. We recently demonstrated that calprotectin better stratifies disease activity than CRP or ESR in RA patients receiving tocilizumab, a biological agent with a dramatic impact on APRs due to its blockage of interleukin 6 [38]. We also found significant associations between calprotectin and disease status in RA and PsA patients treated with TNFi, with calprotectin levels stratifying disease activity more accurately than CRP and ESR in patients with low levels of inflammation [47].

Calprotectin may be useful in certain groups of patients seen in daily clinical practice, such as patients with inflammatory arthralgia, in order to permit an early diagnosis, or patients with recent-onset RA, in whom CRP and ESR levels may be normal. Clinical assessment of RA patients with comorbidities such as fibromyalgia or osteoarthritis may be challenging; in these patients, calprotectin could help rule out inflammatory activity and elucidate the source of pain, guiding therapeutic decisions (e.g., the initiation or tapering of biological treatment). However, at present, according to our results, one of the most interesting clinical applications may be its use in patients in remission or with low disease activity. It is known that the widely used definition of remission based on DAS28 better represents minimal disease activity than remission. Therefore, calprotectin could rule out ongoing inflammation in these patients and 
prevent residual activity being undertreated, with the associated therapeutic and prognostic implications.

In only two reports, both about patients with active RA, have authors analysed the association between calprotectin and MSUS. The first included 20 RA patients starting treatment with ADA [20], and the other comprised 37 RA patients taking csDMARDs [48]. Both studies showed significant associations between calprotectin and MSUS, and the second study suggested that calprotectin might be superior to APRs in monitoring US synovitis. To the best of our knowledge, our present study is the first to include PsA patients and to be focused on patients in remission or with low disease activity receiving biological therapy. Our results show that PsA patients had a lower rate of PDUS synovitis than RA patients did. Moreover, as observed in RA patients, PsA patients with PDUS synovitis had significantly higher calprotectin levels. Calprotectin correlated better and more consistently with MSUS than APRs, and we found significant correlations between calprotectin and PD, SH and US global scores. The US global score combines inflammatory (power Doppler) and structural findings (synovial hypertrophy) in an attempt to capture the whole state of the joint, although previous studies have shown that only the PD score was associated with radiographic progression [49]. In light of the strong correlation in our present study, it seems logical that calprotectin and PDUS synovitis both identify local active synovitis in patients with low levels of disease activity.

This is particularly interesting, considering recent evidence suggesting that TNF blockade depends on the trough serum levels achieved. It is reported that patients with a good response to TNFi therapy have higher drug trough serum levels [24, 25]. Our results show that patients with PDUS synovitis had lower trough serum levels. TNFi trough serum levels inversely correlated with PD in patients receiving ADA and ETN (all $r$ coefficients $>0.50$ ), although they were less accurate than calprotectin in detecting PDUS synovitis. In a previous study, researchers detected no significant influence of anti-TNF pharmacokinetics on the $\mathrm{SH}$ and PD scores in RA patients, although TNFi trough serum levels were not measured in that study [50]. Therefore, our study is the first to be focused on the relationship between TNFi trough serum levels and MSUS assessment in RA and PsA patients.

Our study had some limitations. First, this was a cross-sectional study in patients with long-standing RA and PsA who were receiving prolonged TNFi therapy, and therefore the value of calprotectin, TNFi trough serum levels and PDUS synovitis as prognostic factors for flares or in monitoring therapeutic responses to biological therapy was not evaluated. Second, we used
DAS28 $\leq 3.2$ as the inclusion criterion. This allowed residual tender and/or swollen joints in patients classified as being in remission and did not include the feet. However, it is the most widely used composite articular index, and therefore our results would be clinically applicable. Although the DAS28 was developed to assess disease activity in RA, studies support its use in PsA patients receiving biological therapy [30]. Third, concomitant treatment with csDMARDs, steroids and nonsteroidal anti-inflammatory drugs was not standardized, owing to the observational nature of the study. Finally, US assessment was performed by only one rheumatologist, and therefore inter-observer reliability could not be calculated. This may be a weakness of the study because of the known significant variability between observers in the US assessment of synovitis [51].

\section{Conclusions}

PsA patients in remission or with low disease activity had a lower rate of PDUS synovitis than RA patients. Patients with PDUS synovitis had higher calprotectin levels and lower TNFi trough serum levels, reflecting local, ongoing synovial inflammation. Calprotectin was more accurate than APRs in detecting PDUS synovitis in these patients. TNFi trough serum levels inversely correlated with the PD score and calprotectin levels. Calprotectin and drug trough serum levels may help clinicians identify US active synovitis in RA and PsA patients in clinical remission or with low disease activity treated with TNFi.

\section{Abbreviations \\ ADA, adalimumab; AIC, Akaike information criterion; APR, acute phase reactant; CDAl, Clinical Disease Activity Index; CRP, C-reactive protein; CSDMARD, conventional synthetic disease-modifying anti-rheumatic drug; DAS28-ESR, 28-joint Disease Activity Score based on erythrocyte sedimentation rate; ELISA, enzyme-linked immunosorbent assay; ESR, erythrocyte sedimentation rate; ETN, etanercept; IFX, infliximab; MRP, myeloid-related protein; MSUS, musculoskeletal ultrasound; OMERACT, Outcome Measures in Rheumatoid Arthritis Clinical Trials; PD, power Doppler; PDUS, power Doppler ultrasound; PsA, psoriatic arthritis; RA, rheumatoid arthritis; SDAl, Simple Disease Activity Index; SH, synovial hypertrophy; SJC, swollen joint count; TJC, tender joint count; TNFi, tumour necrosis factor inhibitors; UdAS, ultrasound-defined active synovitis; US, ultrasound; $\mathrm{NV}$, normal value}

\section{Acknowledgements \\ The authors acknowledge the statistical assistance provided by Dr. Loreto Carmona, Dr. María Jesús García de Yébenes y Prous and Miguel Sampayo; the technical advice of David Buss; and the Spanish Rheumatology Society. \\ Funding \\ This work was supported by the Hospital Clinic of Barcelona (grant "Emili Letang 2013") and the Catalan Society of Rheumatology (research grant 2013).}

\section{Authors' contributions}

$R S, J I-M, J R$ and JY conceived of and designed the study. RS, JI-M, JR, MVH, SRC-V and VR-E acquired data. RS, JI-M, JR, VR-E, JDC, MP, SRC-V and MVH analysed and interpreted the data. All authors were involved in drafting the manuscript or revising it critically for important intellectual content, and all authors read and approved the final version to be published. 


\section{Competing interests}

The authors declare that they have no competing interests.

\section{Ethical approval and consent to participate}

This study was conducted in accordance with the Declaration of Helsinki and was approved by the Hospital Clinic of Barcelona Clinical Research Ethics Committee (Reg. 2013/8382). Signed informed consent was obtained from all patients before study enrolment.

\section{Author details}

'Department of Rheumatology, Hospital Clinic, University of Barcelona, Carrer Villarroel 170, 08036 Barcelona, Spain. ${ }^{2}$ Department of Immunology, Hospital Clinic, University of Barcelona, Barcelona, Spain.

\section{Received: 3 February 2016 Accepted: 23 May 2016}

\section{Published online: 08 July 2016}

\section{References}

1. Scott DL. Biologics-based therapy for the treatment of rheumatoid arthritis. Clin Pharmacol Ther. 2012;91:30-43.

2. Smolen JS, Aletaha D, Bijlsma JW, Breedveld FC, Boumpas D, Burmester G, et al. Treating rheumatoid arthritis to target: recommendations of an international task force. Ann Rheum Dis. 2010;69:631-7.

3. Aletaha D, Ward MM, Machold KP, Nell VP, Stamm T, Smolen JS. Remission and active disease in rheumatoid arthritis: defining criteria for disease activity states. Arthritis Rheum. 2005;52:2625-36.

4. Gärtner M, Alasti F, Supp G, Mandl P, Smolen JS, Aletaha D. Persistence of subclinical sonographic joint activity in rheumatoid arthritis in sustained clinical remission. Ann Rheum Dis. 2015;74:2050-3.

5. Anandarajah A, Thiele R, Giampoli E, Monu J, Seo GS, Feng C, et al. Patients with rheumatoid arthritis in clinical remission manifest persistent joint inflammation on histology and imaging studies. J Rheumatol. 2014;41:2153-60,

6. Molenaar ET, Voskuyl AE, Dinant HJ, Bezemer PD, Boers M, Dijkmans BA. Progression of radiologic damage in patients with rheumatoid arthritis in clinical remission. Arthritis Rheum. 2004;50:36-42.

7. Kane D, Balint PV, Sturrock RD. Ultrasonography is superior to clinical examination in the detection and localization of knee joint effusion in rheumatoid arthritis. J Rheumatol. 2003;30:966-71.

8. Joshua F, Edmonds J, Lassere M. Power Doppler ultrasound in musculoskeletal disease: a systematic review. Semin Arthritis Rheum. 2006;36:99-108.

9. Kawashiri SY, Kawakami A, Iwamoto N, Fujikawa K, Satoh K, Tamai M, et al. The power Doppler ultrasonography score from 24 synovial sites or 6 simplified synovial sites, including the metacarpophalangeal joints, reflects the clinical disease activity and level of serum biomarkers in patients with rheumatoid arthritis. Rheumatology (Oxford). 2011;50:962-5.

10. lagnocco A, Finucci A, Ceccarelli F, Perricone C, lorgoveanu V, Valesini G. Power Doppler ultrasound monitoring of response to anti-tumour necrosis factor alpha treatment in patients with rheumatoid arthritis. Rheumatology (Oxford). 2015;54:1890-6.

11. Naredo E, Bonilla G, Gamero F, Uson J, Carmona L, Laffon A. Assessment of inflammatory activity in rheumatoid arthritis: a comparative study of clinical evaluation with grey scale and power Doppler ultrasonography. Ann Rheum Dis. 2005;64:375-81.

12. Kawashiri SY, Suzuki T, Nakashima Y, Horai Y, Okada A, Iwamoto N, et al. Ultrasonographic examination of rheumatoid arthritis patients who are free of physical synovitis: power Doppler subclinical synovitis is associated with bone erosion. Rheumatology (Oxford). 2014;53:562-9.

13. Wakefield RJ, Freeston JE, Hensor EM, Bryer D, Quinn MA, Emery P. Delay in imaging versus clinical response: a rationale for prolonged treatment with anti-tumor necrosis factor medication in early rheumatoid arthritis. Arthritis Rheum. 2007:57:1564-7.

14. Wakefield RJ, Green MJ, Marzo-Ortega H, Conaghan PG, Gibbon WW, McGonagle D, et al. Should oligoarthritis be reclassified? Ultrasound reveals a high prevalence of subclinical disease. Ann Rheum Dis. 2004;63:382-5.

15. Saleem B, Brown AK, Quinn M, Karim Z, Hensor EM, Conaghan P, et al. Can flare be predicted in DMARD treated RA patients in remission, and is it important? A cohort study. Ann Rheum Dis. 2012;71:1316-21.

16. Hansson C, Eriksson C, Alenius GM. S-calprotectin (S100A8/S100A9): a potential marker of inflammation in patients with psoriatic arthritis. J Immunol Res. 2014;2014:696415.
17. Vogl T, Tenbrock K, Ludwig S, Leukert N, Ehrhardt C, van Zoelen MA, et al. Mrp8 and Mrp14 are endogenous activators of Toll-like receptor 4, promoting lethal, endotoxin-induced shock. Nat Med. 2007;13:1042-9.

18. Berntzen HB, Olmez U, Fagerhol MK, Munthe E. The leukocyte protein L1 in plasma and synovial fluid from patients with rheumatoid arthritis and osteoarthritis. Scand J Rheumatol. 1991;20:74-82

19. Hammer $H B$, Ødegård $S$, Fagerhol MK, Landewé $R$, van der Heijde $D$, Uhlig T, et al. Calprotectin (a major leucocyte protein) is strongly and independently correlated with joint inflammation and damage in rheumatoid arthritis. Ann Rheum Dis. 2007;66:1093-7.

20. Hammer HB, Fagerhol MK, Wien TN, Kvien TK. The soluble biomarker calprotectin (a S100 protein) is associated to ultrasonographic synovitis scores and is sensitive to change in patients with rheumatoid arthritis treated with adalimumab. Arthritis Res Ther. 2011;13:R178.

21. Hammer HB, Ødegård S, Syversen SW, Landewé R, van der Heijde D, Uhlig T, et al. Calprotectin (a major S100 leucocyte protein) predicts 10-year radiographic progression in patients with rheumatoid arthritis. Ann Rheum Dis. 2010;69:150-4.

22. García-Arias M, Pascual-Salcedo D, Ramiro S, Ueberschlag ME, Jermann TM, Cara C, et al. Calprotectin in rheumatoid arthritis: association with disease activity in a cross-sectional and a longitudinal cohort. Mol Diagn Ther. 2013;17:49-56.

23. Choi IY, Gerlag DM, Herenius MJ, Thurlings RM, Wijbrandts CA, Foell D, et al. MRP8/14 serum levels as a strong predictor of response to biological treatments in patients with rheumatoid arthritis. Ann Rheum Dis. 2015;74:499-505.

24. Bartelds GM, Krieckaert CL, Nurmohamed MT, van Schouwenburg PA, Lems WF, Twisk JW, et al. Development of antidrug antibodies against adalimumab and association with disease activity and treatment failure during long-term follow-up. JAMA. 2011;305:1460-8.

25. Wolbink GJ, Vis M, Lems W, Voskuyl AE, de Groot E, Nurmohamed MT, et al. Development of antiinfliximab antibodies and relationship to clinical response in patients with rheumatoid arthritis. Arthritis Rheum. 2006;54:711-15.

26. Radstake TR, Svenson M, Eijsbouts AM, van den Hoogen FH, Enevold C, van Riel PL, et al. Formation of antibodies against infliximab and adalimumab strongly correlates with functional drug levels and clinical responses in rheumatoid arthritis. Ann Rheum Dis. 2009:68:1739-45.

27. Takeuchi T, Miyasaka N, Inoue K, Abe T, Koike T, RISING study. Impact of trough serum level on radiographic and clinical response to infliximab plus methotrexate in patients with rheumatoid arthritis: results from the RISING study. Mod Rheumatol. 2009;19:478-87.

28. Wolbink GJ, Voskuyl AE, Lems WF, de Groot E, Nurmohamed MT, Tak PP et al. Relationship between serum trough infliximab levels, pretreatment $C$ reactive protein levels, and clinical response to infliximab treatment in patients with rheumatoid arthritis. Ann Rheum Dis. 2005;64:704-7.

29. Prevoo ML, Hof MA v't, Kuper $H H$, van Leeuwen MA, van de Putte $L B$, van Riel PL. Modified disease activity scores that include twenty-eight-joint counts: development and validation in a prospective longitudinal study of patients with rheumatoid arthritis. Arthritis Rheum. 1995;38:44-8.

30. Fransen J, Antoni C, Mease PJ, Uter W, Kavanaugh A, Kalden JR, et al. Performance of response criteria for assessing peripheral arthritis in patients with psoriatic arthritis: analysis of data from randomised controlled trials of two tumour necrosis factor inhibitors. Ann Rheum Dis. 2006;65:1373-8.

31. Smolen JS, Breedveld FC, Schiff MH, Kalden JR, Emery P, Eberl G, et al. A simplified disease activity index for rheumatoid arthritis for use in clinical practice. Rheumatology (Oxford). 2003:42:244-57.

32. Aletaha D, Nell VP, Stamm T, Uffmann M, Pflugbeil S, Machold K, et al. Acute phase reactants add little to composite disease activity indices for rheumatoid arthritis: validation of a clinical activity score. Arthritis Res Ther. 2005;7:R796.

33. Backhaus M, Burmester GR, Gerber T, Grassi W, Machold KP, Swen WA, et al. Guidelines for musculoskeletal ultrasound in rheumatology. Ann Rheum Dis. 2001;60:641-9.

34. Wakefield RJ, Balint PV, Szkudlarek M, Filippucci E, Backhaus M, D'Agostino $M A$, et al. Musculoskeletal ultrasound including definitions for ultrasonographic pathology. J Rheumatol. 2005;32:2485-7.

35. Szkudlarek M, Court-Payen M, Jacobsen S, Klarlund M, Thomsen HS, Østergaard M. Interobserver agreement in ultrasonography of the finger and toe joints in rheumatoid arthritis. Arthritis Rheum. 2003;48:955-62.

36. Naredo E, Collado P, Cruz A, Palop MJ, Cabero F, Richi P, et al. Patients with rheumatoid arthritis in clinical remission and ultrasound-defined active synovitis exhibit higher disease activity and increased serum levels of angiogenic biomarkers. Arthritis Res Ther. 2014;16:R5. 
37. Ramírez J, Ruíz-Esquide V, Pomés I, Celis R, Cuervo A, Hernández MV, et al. Longitudinal power Doppler ultrasonographic assessment of joint inflammatory activity in early rheumatoid arthritis: predictive value in disease activity and radiologic progression. Arthritis Rheum. 2007:57:116-24.

38. Inciarte-Mundo J, Ruiz-Esquide V, Hernández MV, Cañete JD, Cabrera-Villalba SR, Ramirez J, et al. Calprotectin more accurately discriminates the disease status of rheumatoid arthritis patients receiving tocilizumab than acute phase reactants. Rheumatology (Oxford). 2015;54:2239-43.

39. Ruiz-Argüello B, del Agua AR, Torres N, Monasterio A, Martínez A, Nagore D. Comparison study of two commercially available methods for the determination of infliximab, adalimumab, etanercept and anti-drug antibody levels. Clin Chem Lab Med. 2013;51:e287-9.

40. Filippucci E, lagnocco A, Salaffi F, Cerioni A, Valesini G, Grassi W. Power Doppler sonography monitoring of synovial perfusion at wrist joints in patients with rheumatoid arthritis treated with adalimumab. Ann Rheum Dis. 2006;65:1433-7.

41. Brown AK, Quinn MA, Karim Z, Conaghan PG, Peterfy CG, Hensor E, et al. Presence of significant synovitis in rheumatoid arthritis patients with disease-modifying antirheumatic drug-induced clinical remission: evidence from an imaging study may explain structural progression. Arthritis Rheum. 2006;54:3761-73.

42. Brown AK, Quinn MA, Karim Z, Conaghan PG, Peterfy CG, Hensor E, et al. An explanation for the apparent dissociation between clinical remission and continued structural deterioration in rheumatoid arthritis. Arthritis Rheum. 2008:58:2958-67.

43. Machado FS, Natour J, Takahashi RD, de Buosi AL, Furtado RN. Sonographic assessment of healthy peripheral joints: evaluation according to demographic parameters. Ultrasound Med. 2014;33:2087-98.

44. Wakefield RJ, D'Agostino MA, Naredo E, Buch MH, lagnocco A, Terslev L, et al. After treat-to-target: can a targeted ultrasound initiative improve RA outcomes? Ann Rheum Dis. 2012;71:799-803.

45. Gärtner M, Mandl P, Radner H, Supp G, Machold KP, Aletaha D, et al. Sonographic joint assessment in rheumatoid arthritis: associations with clinical joint assessment during a state of remission. Arthritis Rheum. 2013:65:2005-14

46. Charles P, Elliott MJ, Davis D, Potter A, Kalden JR, Antoni C, et al. Regulation of cytokines, cytokine inhibitors, and acute-phase proteins following anti-TNF-therapy in rheumatoid arthritis. J Immunol. 1999;163:1521-8.

47. Inciarte-Mundo J, Hernández MV, Ruiz-Esquide V, Cabrera-Villalba SR, Ramirez J, Cuervo A, et al. Serum calprotectin more accurately discriminates the inflammatory disease activity of RA patients receiving TNF inhibitors than acute phase reactants. Arthritis Care Res. 2015. doi:10.1002/acr.22795.

48. Hurnakova J, Zavada J, Hanova P, Hulejova H, Klein M, Mann H, et al. Serum calprotectin (S100A8/9): an independent predictor of ultrasound synovitis in patients with rheumatoid arthritis. Arthritis Res Ther. 2015;17:252.

49. Naredo E, Rodríguez M, Campos C, Rodríguez-Heredia JM, Medina JA, Giner $E$, et al. Validity, reproducibility, and responsiveness of a twelve-joint simplified power Doppler ultrasonographic assessment of joint inflammation in rheumatoid arthritis. Arthritis Rheum. 2008;59:515-22.

50. Naredo E, Hinojosa M, Valor L, Hernández-Flórez D, Mata-Martínez C, Serrano-Benavente B, et al. Does ultrasound-scored synovitis depend on the pharmacokinetics of subcutaneous anti-TNF agents in patients with rheumatoid arthritis? Rheumatology (Oxford). 2014;53:2088-94.

51. Naredo E, Wakefield RJ, lagnocco A, Terslev L, Filippucci E, Gandjbakhch F, et al. The OMERACT ultrasound task force-status and perspectives. J Rheumatol. 2011;38:2063-7.

\section{Submit your next manuscript to BioMed Central and we will help you at every step:}

- We accept pre-submission inquiries

- Our selector tool helps you to find the most relevant journal

- We provide round the clock customer support

- Convenient online submission

- Thorough peer review

- Inclusion in PubMed and all major indexing services

- Maximum visibility for your research

Submit your manuscript at www.biomedcentral.com/submit
Biomed Central 